
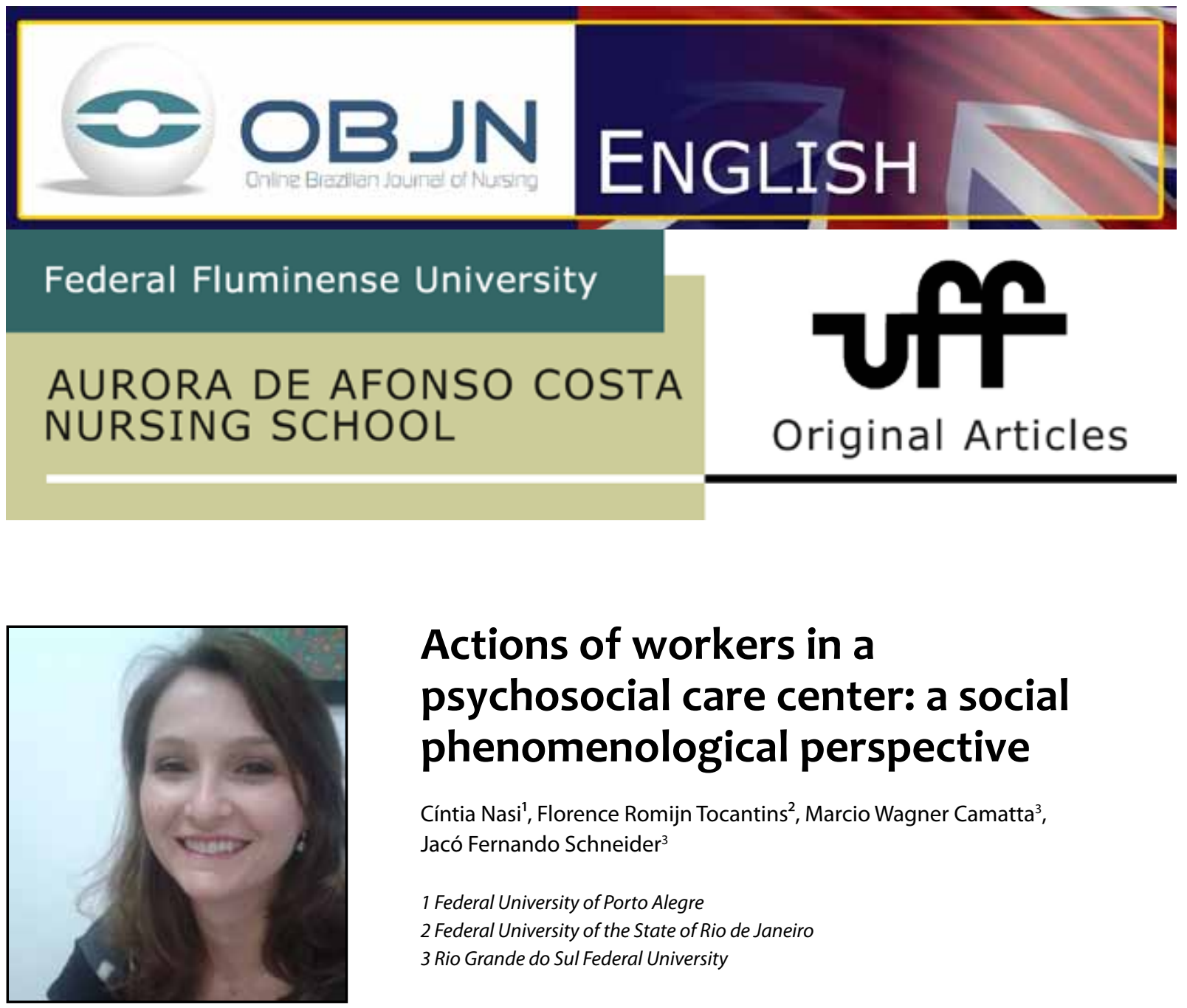

\title{
Actions of workers in a psychosocial care center: a social phenomenological perspective
}

\author{
Cíntia Nasi ${ }^{1}$, Florence Romijn Tocantins ${ }^{2}$, Marcio Wagner Camatta ${ }^{3}$, \\ Jacó Fernando Schneider ${ }^{3}$ \\ 1 Federal University of Porto Alegre \\ 2 Federal University of the State of Rio de Janeiro \\ 3 Rio Grande do Sul Federal University
}

\begin{abstract}
Aim: To understand the significance of the actions of workers in a Psychosocial Care Center (CAPS). Method: This is a qualitative study, using the framework of social phenomenology by Alfred Schutz, conducted in a Psychosocial Care Center in Western Santa Catarina. Interviews were conducted with 14 workers of the service. Results: Workers intend to promote improvements in users' treatment; they seek to promote autonomy, quality of life and social reinsertion and await improvements in the municipal public administration to provide a service with adequate conditions for users. Conclusion: The study gave visibility to workers' actions in their daily lives, making it possible to involve them in the reflections regarding the way the service is structured so that they build new possible ways to qualify their actions.
\end{abstract}

Descriptors: Mental Health; Mental Health Services; Nursing; Qualitative Research. 


\section{INTRODUCTION}

The Psychosocial Care Centers (CAPS) are elements of the mental health care network responsible for the demand of users in a given territory. CAPS have the potential to strengthen the principles of psychiatric reform to the extent that emphasizes the uniqueness of its users and provides comprehensive care, with dialogic and humanized relationships.

The CAPS units have strategic value for Brazilian psychiatric reform, especially because they allow the organization of a substitutive network for the psychiatric hospitals and asylum models in the country. The CAPS units are community open health services; they are benchmarks for people with severe and persistent mental disorders and are designed to make clinical follow-up and social reinsertion through work, recreation, exercise of civil rights and the strengthening of family and community ties ${ }^{(1)}$. The purpose of CAPS is to offer a service that does not isolate users, but which seeks to reinsert them in the family, community and productive life by the rescue of their self-esteem and bond restructuring ${ }^{(2)}$.

From this perspective, the service provided to users and family members at CAPS should be developed by employees in different areas, overcoming the classic settings that have traditionally operated in the area of mental health: psychologist, psychiatrist, nurse and social worker. Thus, in the psychosocial services, workers from areas such as occupational therapists, the arts and physical education professionals should be added as well. It is recognized, however, that the configuration of the multidisciplinary team may vary according to the characteristics of the service and demands of users. Therefore, it is of utmost importance that the group operates through an exchange and complementarity of its respective knowledge in the everyday actions of the service.
The new proposed work organization allows all professionals to feel part of the team, being respected, recognized, and valued participants in the psychosocial rehabilitation pro$\operatorname{cess}^{(3)}$. In addition, the CAPS also seeks to engage users' families in the treatment and care therapy, which is understood as a fundamental part of the satisfactory progress of the user in terms of the psychosocial aspects of care ${ }^{(4)}$.

In the new configuration of mental health work with the organization of a network of community services, it is essential to know the motivations of workers regarding the actions they develop for the service, which are aimed at providing a service to users. The study will allow the observation of the actions developed by the CAPS workers and their motivations as to the treatment of users. Thus, the aim of this study was to understand the meaning of the actions of these employees in a CAPS unit, from the perspective of social phenomenology.

\section{METHODOLOGY TRAJECTORY}

This was a qualitative study using a phenomenological approach and the theoretical-philosophical framework of social phenomenology of Alfred Schutz ${ }^{(5)}$.

To understand the significance of the actions of the CAPS workers, the basis of Schutz's conception, in terms of the definition of social action was considered. Thus, the actions of employees are those seen as motivated behavior, motives that Schutz ${ }^{(5)}$ classified into two sets: the reasons for and the reasons why. The reasons for are related to the purpose because of which the action was taken; they refer to the future. On the other hand, the reasons why refer to past experiences of the subject. Such experiences determine how they act ${ }^{(5)}$.

The field of study of this research was a 
CAPS II, located in the western region of the state of Santa Catarina, Brazil. The subjects were 14 workers in the CAPS, including four doctors, two psychologists, a nurse, a social worker, three nursing assistants, an administrative technician and two community health agents (CHA).

Data collection was through phenomenological interviews ${ }^{(6)}$ which were carried out in January and February 2011 in the premises of CAPS. The following guiding questions were used:"Tell me what actions you have developed in CAPS?" and "What were your aims in such actions?" The interviews were recorded on digital audio and transcribed in full. The number of subjects was not previously set up; the interviews took place until the moment we realized that there was repetition of dialogue ${ }^{(7)}$, in terms of the actions and motivations of CAPS's workers.

The analysis of information was conducted by following the steps recommended by researchers from social phenomenology ${ }^{(6,8,9)}$. A comprehensive reading and critical analysis of the speeches allowed us to identify and describe the significance of the action - categorization with consequent understanding of the phenomenon investigated after identifying the reasons for the action. These causes reveal the action of the actor's intentionality in the social world as action in progress or with a view to the future, unveiling their expectations, aspirations and desired goals. The categories that emerged from this analysis, based on the social phenomenology of Alfred Schutz, were an objective synthesis of the meanings of the actions that arose from the experiences of the subjects and were called concrete categories $^{(6)}$.

The ethical aspects of research involving human beings were observed. Signing the free and informed consent form guaranteed confidentiality and anonymity of the subjects participating in the research. The research project was approved by the Research Ethics Committee of the Community University of Chapecó Region (UNOCHAPECÓ), under the opinion no. 263/10.

\section{RESULTS}

The actions developed by workers are related to those developed specifically within the CAPS and others are aimed at the society. The actions in the CAPS were aimed at assisting the users and their families; the bond with users; the interference of municipal public policies in their work; the establishment of relationships with teammates; in internship supervision and coping with the stigma of mental health. As to the actions in the community space, workers reported the articulation of CAPS with primary care and other mental health actions directed to the community.

From the interviews, we sought to identify the reasons for the actions of workers in the CAPS, that is, the intentions of service employees to develop their activities, and to reveal the meaning.

\section{Workers aimed at promoting the autonomy and quality of life of users}

The study focused on the prevention of the crises of users, so that the mental disorders of users did not get any worse.

\footnotetext{
"We want to get patients to remain as they are, stable [...] to prevent the most serious crises, which are those that end up resulting in hospitalization." (E1)
}

Other workers also specified that they made users aware that the treatment would present results in the future.

\footnotetext{
"I hope that we can convey to them that up front there will be a result of all that,
} 
because it is a long-term thing [...] or for the rest of their lives [...] I hope there is some reflection up ahead." (E7)

Employees sought a reduction of the characteristic symptoms of mental disorders, promoting a recovery in mental health and a better quality of life for users.

"I hope they get better [...] in their physical well-being, their mental well-being." (E4)

"Provide an improvement in the mental health of your patient." (E6)

"What we expect is to improve the quality of life of patients, improve their family life [...] link patients to society to improve their quality of life." (E11)

They also considered that they their work is focused on the promotion of mental health and not only on the mental disorders.

"My objective [...] is always to seek the potential of patients and ask them how they are feeling and how they deal with their problems. [...] They have a task, a problem that could be any disease, but their lives are not just about it." (E9)

.However, despite pointing out that one of the subjects has the goal of working to promote mental health, it acknowledges that he is still focused on mental illness, especially given the severity of the condition of users coming to the service.
When they get here they are already in the final stages and we cannot do a preventive work, for example, and my ultimate goal is to, one day, achieve prevention." (E2)

Workers hope that, with the development of their actions in the CAPS work routine; they will be able to encourage users to seek to exercise their citizenship and their potential outside the service area.

\begin{abstract}
"They are developing their potential and they are able to exercise their citizenship to criticize various things that go far beyond their pathologies. They can look at their lives and the entire socio-cultural, economic and political context, not just the biological and biomedical issues that are part of their illness. It has been an exercise in working with their potential." (E9)
\end{abstract}

In their actions, they seek to encourage the autonomy and empowerment and self-care of users across their lives.

\begin{abstract}
"[...] His empowerment regarding his stuff, of his taking charge of himself [...] I think workshops and therapeutic groups have this purpose even in a home visit. Because you interact with them make them rediscover their autonomy." (E6)
\end{abstract}

"We help with everything, so they can be a little independent." (E13)

With the work performed at CAPS, they also hope to promote the social reintegration of users so that they have greater social interaction, 
participate in various activities in the society and return to the labor market.

"We guide them so they have social participation, better living habits, interaction with the society, have activities instead of staying home alone, have hobbies, try to do some physical activity, for example, and not be restricted to only taking medicines and staying indoors and come to CAPS." (E8)

During the interviews, workers highlighted that they intended to establish a bond of relationship with users.

"[...]Their relationship; they are increasingly linked to us." (E4)

"I think the bond we build with them is very good, such hospitality is an expectation, and is something that we always expect. It is not very easy, they are tightly closed, so creating this bond is what we expect." (E10)

\section{DISCUSSION}

In their daily lives, officials try to keep the mental disorders of the users in a stable condition, preventing them from going into crisis and worsening their symptoms. We identified that the actions that allow patients to remain in a stable mental condition show that these are forms of intrinsic importance in the workers' daily life, that is, an action that arouses interest in them.

Schutz ${ }^{(5)}$ described a relevance system, which is determined by the interests at hand. It is this interest that motivates thinking, designing and acting. However, there is no interest at hand when isolated, but rather a variety of interests called in everyday life plans (of life, of work, of thought). The intrinsic relevance is the result of the chosen interests, spontaneously established to solve problems by thinking ${ }^{(5)}$.

Although some workers highlight the critical character of mental disorders and aim not to worsen the mental health situation of these users, the team also points out that, during their actions, they aim at the improvement of patients. They seek the reduction of the characteristic symptoms of mental disorders, promoting a recovery in their mental health, the improvement of their quality of life and a better integration into society.

It was observed that the team believes that their work is focused on the promotion of mental health, and is not only for mental illness. Such an inversion of the attention of logic, of a service which is aimed at mental illness patients and the sole remission of the psychiatric symptoms of the subjects for a treatment that values the promotion of mental health and is focused on the patient, appears with the movement of the Brazilian psychiatric reform and the transformation of the asylum mode for the psychosocial.

The process of Brazilian psychiatric reform aims at making a break with the traditional model, which is based on the disease-healing principle and deals with the health-disease process in a predominantly organic way, with careful strategies focused on symptoms. The proposal developed the reform, so that the psychosocial care strategy requires overcoming this paradigm to another to understand the health-disease as a result of complex social processes, which value the user as a subject and require an interdisciplinary and intersectoral approach, with the construction of a network of care ${ }^{(10)}$. The making of a care service that aims at comprehensive care should focus on investing, not only in the biomedical aspects, but also to know and understand 
the subject with its subjectivity, its history and its social relations ${ }^{(8)}$.

It was assumed that the workers return their focus to the promotion of mental health using their stock of knowledge about the modalities of attention of psychosocial care modes. This is because a person has, at any time, a stock of knowledge at hand that works as a code of interpretations of their past and present experiences, and also determines their anticipation of things to come. This stock of knowledge exists in a continuous stream and changes in terms of length and structure ${ }^{(5)}$.

The workers hope that, with the development of their actions in the CAPS work routine, they will be able to encourage users to exercise their citizenship and their capabilities outside of the service area. These actions include both the stimulus for users to be able to organize their household chores in their homes, and also to seek work in society.

The employees seek to encourage the autonomy, empowerment, and self-care of users regarding their lives. Through the movements for psychiatric reform, we seek to work towards the empowerment of users and increase their contractual power in society ${ }^{(11)}$. Empowerment encompasses a set of strengthening strategies of power for the autonomy of the subjects. Mental health is related to a perspective of power strengthening, participation and organization of users and families in the care of the context of mental health, as well as rights defense strategies to change the relative culture of illness and mental health, of the exercise of social control in the health system and social activism ${ }^{(12)}$.

Workers seek to promote the social reintegration of users, so that they have greater social interaction, participate in various activities in society and return to the labor market. Concerns such as these are essential in a substitutive service such as CAPS, which, not only has the role of targeted care for psychiatric treatment, but also an important goal of working with the psychosocial rehabilitation of users and their involvement in various social activities.

It is recognized that CAPS must promote actions to enable the psychosocial rehabilitation of their patients through community activities for the social integration of individuals in psychological distress in the community. With this understanding, and to ensure that the CAPS promote this psychosocial rehabilitation, it is necessary to have the involvement and mobilization of users, family members, service workers and the community in general ${ }^{(13)}$.

The employees also highlighted the importance of the establishment of the bond and greater social interaction with the users. Namely, the establishment of ties in mental health at work is of great importance as it is related to the development of direct social relationships, in face-to-face situations. Social relations are established by users in everyday life, which is an intersubjective world shared among equals ${ }^{(5.14)}$. Face-to-face social relations presuppose a real simultaneity of each of the different consciousness chains; that is, when both are sharing a common time and space ${ }^{(5)}$. The bond between workers and users is a therapeutic tool, occurring in daily social relations, which from the perspective of social phenomenology, emerges in the face-to-face intersubjective relationships, where aspects of uniqueness are captured mutually.

Through the emergence of concrete categories, it was possible to prepare the typical aspects of the action of professionals, which are expressed when it is intended that users have improvements in their treatment, quality of life, mental health, social reintegration, in establishing ties and social interaction with other users. 


\section{CONCLUSION}

This study has examined the significance of the actions of CAPS workers from their own descriptions, revealing the intentions of their actions, from the perspective of social phenomenology.

The actions of the workers of a CAPS unit have expressed that it is the intention of users to improve their treatment in relation to mental health and their daily activities. The subjects demonstrated the intention of their actions towards the promotion of mental health, users' social reinsertion and the establishment of bonding and social interaction.

From the theoretical and methodological framework adopted in this study, it was shown that the intentions and motivations of workers have pointed to the development of their work following the assumptions of psychosocial care and the very conceptions of psychiatric reform.

However, it was observed that more studies are needed to explore and analyze this social reality using the perspective of the meaning of action to other actors involved in this care scenario, such as users and families, since a comparison of these perspectives can reveal convergence or divergence of interests between social groups. Studies within the space of CAPS should also be continued in order to strengthen this type of service along with a network of mental health care.

\section{REFERENCES}

1. Brasil. Ministério da Saúde. Centros de Atenção Psicossocial - CAPS [homepage] . Available from: http://portal.saude.gov.br/portal/saude/visualizar_texto.cfm?idtxt=29797

2. Schrank G, Olschowsky A. Centers of psycho-social attention and the strategies for family insertion. Rev Esc Enferm USP 2008;42(1):127-34.

3. Filizola CLA; Milioni, DB; Pavarini, $\mathrm{SCl} A$ vivência dos trabalhadores de um CAPS diante da nova organização do trabalho em equipe. Rev Eletr Enferm [internet] 2008 [cited 2010 may 15]; 10(2): 491-503. Available from: http://www.revistas.ufg. br/index.php/fen/article/view/8061/5828.

4. Mielke FB, Kantorski LP, Jardim VMR, Olschowsky A, MachadoMS. Mental care delivered in psychosocial care centers (CAPS) from the viewpoint of the professionals. Cienc. saude colet. 2009; 14(1):159-164.

5. Schutz A. Sobre Fenomenologia e Relações Sociais. Petrópolis: Vozes; 2012.

6. Jesus MCP, Capalbo C, Merighi MAB, Oliveira DM Tocantins FR, Rodrigues BMDR, Ciuffo LL. The social phenomenology of Alfred Schütz and its contribution for the nursing. Rev. esc. Enferm. USP. $2013 ; 47$ ( 3 ): 736-741

7. Moraes EL, Santos MJ, Merighi MAB, Massarollo MCKB. Experience of nurses in the process of donation of organs and tissues for transplant Rev. Latino-Am. Enfermagem. 2014; 22(2):226-233.

8. Camatta MW, Wetzel C, Schneider JF. Users' expectations with regard to mental health actions: a phenomenological study. Online braz j nurs [periodic online]. 2012 Dec [cited year mouth day]; 11 (3):668-82. Available from: http://www. objnursing.uff.br/index.php/nursing/article/ view/3908

9. Souto RQ, Merighi MAB, Guruge S, Jesus MCP. Older Brazilian women's experience of psychological domestic violence: a social phenomenological study. Int J Equity Health. 2015; 14(44).

10. Yasui S, Costa-Rosa A. A Estratégia Atenção Psicossocial: desafio na prática dos novos dispositivos de Saúde Mental. Saúde em Debate 2008; 32( 78/79/80): 27-37.

11. Almeida KS, Dimenstein M, Severo AK. Empowerment and psychosocial care: notes on a mental health association. Interface - Comunic Saude Educ 2010; 14(34):577-89.

12. Vasconcelos EM. Abordagens psicossociais II: reforma psiquiátrica e saúde mental na ótica da cultura e das lutas populares. São Paulo: Hucitec; 2008

13. Nasi C,Schneider J. Actividades cotidianas de usuarios de un servicio de salud mental: una investi- 
gación fenomenológica. Index Enferm [internet] 2010[cited 2011 abr 15]; 19(4): 249-53. Available from: http://scielo.isciii.es/scielo.php?script=sci_ arttext\&pid=S1132-12962010000300004\&lng=p t\&nrm=iso\&tlng=es

14. Nasi C; Schneider JF. Social relationships in the quotidian of users of a psychosocial care center: a phenomenological study. Online Brazilian Journal of Nursing [internet]. 2010 April [Cited 2013 jun 03]; 9(1). Available from: http://www. objnursing.uff.br/index.php/nursing/article/ view/j.1676-4285.2010.2745/html_96

Authors' contributions:

Cíntia Nasi: she participates in the design stages of the research, data collection, analysis and interpretation of results and final wording.

Florence Romijn Tocantins: she participates in the design stages of research, analysis and interpretation of results and final wording.

Marcio Wagner Camatta: he participates in the design stages of research, analysis and interpretation of results and final wording.

Jacó Fernando Schneider: he participates in the design stages of research, analysis and interpretation of results and final wording.
All authors participated in the phases of this publication in one or more of the following steps, in According to the recommendations of the International Committee of Medical Journal Editors (ICMJE, 2013): (a) substantial involvement in the planning or preparation of the manuscript or in the collection, analysis or interpretation of data; (b) preparation of the manuscript or conducting critical revision of intellectual content; (c) approval of the versión submitted of this manuscript. All authors declare for the appropriate purposes that the responsibilities related to all aspects of the manuscript submitted to OBJN are yours. They ensure that issues related to the accuracy or integrity of any part of the article were properly investigated and resolved. Therefore, they exempt the OBJN of any participation whatsoever in any imbroglios concerning the content under consideration. All authors declare that they have no conflict of interest of financial or personal nature concerning this manuscript which may influence the writing and/or interpretation of the findings. This statement has been digitally signed by all authors as recommended by the ICMJE, whose model is available in http://www. objnursing.uff.br/normas/DUDE_eng_13-06-2013.pdf

Received: 09/02/2013

Revised: 09/24/2015

Approved: 10/01/2015 